\title{
Prevalence of Metabolic Syndrome in HIV-Infected Cameroonian Patients
}

\author{
Henriette Thérèse Dimodi1,2, Lucien Sone Etame ${ }^{1,2}$, Boris Signing Nguimkeng1, \\ Florine Essouman Mbappe1, Nadine Essola Ndoe', Jacob Nkougni Tchinda', \\ J. Justin Abega Ebene1, Françoise Raïssa Ntentié1,3, G. Boris Azantsa Kingue1,4, \\ Mary-Ann Mbong Angie', Ghislain Djiokeng Paka1,5, Charles Kouanfack ${ }^{6}$, \\ Judith Laure Ngondi ${ }^{1}$, Julius Oben Enyong ${ }^{*}$ \\ ${ }^{1}$ Department of Biochemistry, Yaounde I University, Yaounde, Cameroon \\ ${ }^{2}$ Centre for Food and Nutrition Research (CRAN), Institute of Medical Research and Medicinal Plants Study \\ (IMPM), Ministry of Scientific Research and Innovation, Yaounde, Cameroon \\ ${ }^{3}$ Higher Teacher's Training College (ENS), University of Maroua, Maroua, Cameroon \\ ${ }^{4}$ Department of Biochemistry and Molecular Biology, University of Buea, Buea, Cameroon \\ ${ }^{5}$ INRS-Institut Armand Frappier, Laval, Québec, Canada \\ ${ }^{6}$ Central Hospital, Yaounde, Cameroon \\ Email: ${ }^{*}$ juliusoben@hotmail.com
}

Received 24 October 2013; revised 24 November 2013; accepted 30 November 2013

Copyright (C) 2014 by authors and Scientific Research Publishing Inc.

This work is licensed under the Creative Commons Attribution International License (CC BY).

http://creativecommons.org/licenses/by/4.0/

(c) (i) Open Access

\section{Abstract}

Aims: Metabolic complications related to antiretroviral therapy are rarely investigated among HIV-infected patients in Cameroon. The study reports the prevalence of metabolic syndrome and its individual components among HIV-infected Cameroonians. Materials and Methods: We conducted a prospective, cross-sectional study of the prevalence of metabolic syndrome among 492 patients (338 women, 117 men; age range 20 years) recruited at a reference centre, the day hospital, Central Hospital in Yaounde between September 2009 and September 2010. Metabolic syndrome was defined according to IDF (International Diabetes Federation) and NCEP ATP III (National Cholesterol Education Program Adult Treatment Panel III) criteria relative to obesity, glycemic, lipid, arterial blood pressure parameters. Results: The prevalence of metabolic syndrome was $32.8 \%$ according to IDF and $30.7 \%$ by NCEP $(p=0.0001)$. The prevalences of individual components according to IDF and NCEP were as follows: abdominal obesity $(40.5 \% ; 26.9 \%$ respectively), hypertriglyceridemia (55.5\%), low HDL cholesterol (42.5\%), systolic hypertension (38.2\%) diastolic hypertension $(28.5 \%)$, hyperglycemia $(31.2 \% ; 1.3 \% \mathrm{p}=\mathbf{0 . 0 0 0 1})$. The prevalence of metabolic syndrome was $36 \%$ in patients under HAART, $23.4 \%$ in naive, $(p=0.0001)$. Conclusion: The prevalence of metabolic syndrome depends on the presence and the type of HAART used, the definition and the gender.

${ }^{*}$ Corresponding author. 


\section{Keywords}

\section{HIV; Antiretroviral Drugs; Abdominal Obesity; Dyslipidemia; Hypertension; Hyperglycemia; Metabolic Syndrome; Prevalence}

\section{Introduction}

HAART has resulted in significant reductions of morbidity and mortality associated with HIV infection [1]. HIV-infected patients are now expected to live longer. Unfortunately, a life with the chronic viral infection, exposures to medications that carry their own toxicities and side effects are now associated with increased risk of developing health complications. HAART has been associated with metabolic complications that may increase patients' risk of cardiovascular disease [2]. Specific antiretroviral therapies (protease inhibitors) have been shown to increase proatherogenic lipid levels and contribute to the development of insulin resistance and visceral fat accumulation [3]. The latter components are characteristics of the metabolic syndrome (MetS) [4]. This syndrome is affecting the general population in epidemic proportions and it is frequently associated with risk factors for diabetes and cardiovascular disease [5]. The metabolic syndrome represents a cluster of metabolic risk factors: central obesity, dyslipidemia, elevated blood pressure, abnormal glucose tolerance, insulin resistance. Insulin resistance was initially the main focus of MetS, but adiposity, sedentary lifestyle, dietary and genetic factors have also received much attention when considering the pathogenesis of the MetS [6]. Several features of the MetS in the general population are also found in HIV-infected patients [7]. Some studies in HIVinfected persons have shown worldwide prevalence between $17 \%$ to $42 \%$ [8]. Jerico [9] reported a prevalence of $17 \%$ among Spanish patients receiving HAART. In Botswana and Nigeria the prevalence of $7.7 \%$ and $11 \%$ respectively has been reported [10] [11]. However, many data of metabolic complications in HIV-infected subjects in then sub-Saharan region remain scarce. Furthermore, the biochemical markers like liver function tests and kidney function tests are frequently investigated in the management of HIV therapy in developing countries particularly in Cameroon but the therapeutic guidelines recommend testing of lipids abnormalities only once per year. So the findings of this study may first of all help to know the extent of the problem in HIV-infected cameroonians and secondly may point out the need for a policy shift with regard to the frequent testing of metabolic abnormalities in this population. This will assist clinicians in taking the necessary precautionary measures in the management of these complications in HIV-infected people on antiretroviral therapies.

\section{Material and Methods}

\subsection{Study Design}

This was a prospective, cross-sectional evaluation of patients' risk for developing the metabolic syndrome.

\subsection{Place and Duration of Study}

Day hospital of the Central hospital, Yaounde; Department of Biochemistry, Yaounde I University, between September 2009 and September 2010.

\subsection{Methodology}

We performed a prospective, cross-sectional evaluation of HIV-infected patients coming for their routine medical visits, at the day hospital of the Central hospital in Yaounde over a period of one year (September 2009 to September 2010. After giving their informed consent, all participants were asked to complete a self-administered questionnaire with information regarding age, sex, tobacco and alcohol use, characteristics related to HIV infection and antiretroviral therapies, confirmation was done using medical records. The study was approved by the National ethical committee and the Ministry of Public Health. Patients younger than 20 years of age, pregnant and breastfeeding women, history of therapies that affect lipid and carbohydrates metabolism were excluded from the analysis.

\subsubsection{Blood Pressure Assessment and Anthropometric Measurements}

Blood pressure was assessed using a validated electronic device (OMRON) after the subjects were seated and 
rested for at least 5 minutes. Waist circumference was measured with a flexible inelastic tape placed on the midpoint between the lower rib margin and the iliac crest in a perpendicular plane to the long axis of the body. Height was determined without shoes using a portable stadiometer. Weight and body fats were measured by a Tanita scale; patients were fully dressed, without heavy clothing or shoes. Body mass index (BMI) was calculated as weight in kilograms (Kg) divided by the Square of the height in meters (m).

\subsubsection{Laboratory Analysis}

Glucose was measured by the oxydase method [12]. Total cholesterol [13] and triglycerides [14] were quantified using enzymatic methods. HDL cholesterol was measured using a heparin manganese precipitation of Apo B-containing lipoproteins [13]. LDL cholesterol was calculated using the Friedwald equation [15] CD4 cell count was determined by flow cytometry.

\subsubsection{Definitions of Metabolic Syndrome and HAART}

The presence of MetS was evaluated using National Cholesterol Education Program Adult Treatment Panel III (NCEP ATP III) and International Diabetes Federation (IDF) definitions. According to NCEP ATP III [16], metabolic syndrome was defined as having $\geq 3$ of the following criteria: abdominal obesity (waist circumference $\geq 102 \mathrm{~cm}$ for men and $\geq 88 \mathrm{~cm}$ for women), fasting triglyceride levels $\geq 150 \mathrm{mg} / \mathrm{dL}$, high-density lipoprotein (HDL) cholesterol level $<40 \mathrm{mg} / \mathrm{dL}$ for men and $<50 \mathrm{mg} / \mathrm{dL}$ for women, fasting glucose levels $\geq 110 \mathrm{mg} / \mathrm{dL}$, or hypertension (blood pressure $\geq 130 / 85 \mathrm{~mm} \mathrm{Hg}$ or current receipt of medication for hypertension). According to IDF criteria [17], waist circumference $(>80 \mathrm{~cm}$ in women and $>94 \mathrm{~cm}$ ) is a prerequisite in addition to $\geq 2$ of the following components: fasting triglyceride levels $\geq 150 \mathrm{mg} / \mathrm{dL}$, high-density lipoprotein (HDL) cholesterol level $<40 \mathrm{mg} / \mathrm{dL}$ for men and $<50 \mathrm{mg} / \mathrm{dL}$ for women, fasting glucose levels $\geq 100 \mathrm{mg} / \mathrm{dL}$, or hypertension (blood pressure $\geq 130 / 85 \mathrm{~mm} \mathrm{Hg}$ or current receipt of medication for hypertension).

\subsubsection{Definitions of HAART}

HAART was defined as the use of 2 nucleosides (NRTIs) and a non nucleoside reverse-transcriptase inhibitor (NNRTI), 2 NRTIs and a PI (protease inhibitor), or 3 NRTIs.

\subsection{Statistical Methods}

Data were analyzed using the SPSS software package, version 16.0 (SPSS 16.0). All the data were expressed as means \pm standard error of means and frequencies (\%). Student's $t$ test or Analysis of variable (ANOVA) was carried out in order to assess differences between means. P value $\leq 0.05$ was considered statistically significant.

\section{Results and Discussion}

Among 492 patients recruited at a reference centre, the day hospital of the Yaounde Central Hospital from September 2009 to September 2010, 29 were excluded for age, those having metabolic, endocrine, neuronal diseases, pregnant or breast-feeding women. In this study, we described the prevalence of components and the MetS and analyzed some factors such as sex or HAART exposure associated with the syndrome.

\subsection{Socio-Demographic, HIV-Related Characteristics of the Study Population}

Of these 463 patients, $(74.7 \%, n=338)$ women and $(25.3 \%, n=117)$ men; $(75.19 \%, n=348)$ were on combination therapies and $(24.81 \%, n=115)$ naive. Most of the patients were symptomatic $(42.92 \%, n=200)$ and in the $\mathrm{B}$ stage of the infection according to Center for Disease Control (CDC). The majority $(72.79 \%, \mathrm{n}=337$ ) was taking the association of 2 NRTIs and 1 NNRTI, made up mostly of 3TC + AZT + NEV, $(31 \%, n=118)$; 3TC + AZT + EFV, (27.6 \%, $n=93)$; d4T + 3TC + EFV, $(10.1 \%, n=34) ; d 4 T+3 T C+N E V,(24.6 \%, n=83)$. Frequent alcohol drinking was observed in $(32.2 \%, \mathrm{n}=163)$ and $(73.76 \%, \mathrm{n}=341)$ have a low rate of doing physical exercises. These are shown in Table 1.

\subsection{Prevalence of Individuals' Components of the Metabolic Syndrome According to IDF and ATP III Definitions}

The prevalence of abdominal obesity, $(40.5 \%, n=118)$ and hyperglycemia, $(31.2 \%, n=92)$ are high according 
Table 1. Socio-demographic, HIV-related characteristics of the study population.

\begin{tabular}{|c|c|}
\hline Parameters & Values \\
\hline \multicolumn{2}{|l|}{ Sex } \\
\hline Men & $117(25.3)$ \\
\hline Women & $338(74.7)$ \\
\hline \multicolumn{2}{|l|}{ Age (years) } \\
\hline $20-29.9$ & $69(15.1)$ \\
\hline $30-39.9$ & $179(39.1)$ \\
\hline $40-49.9$ & $133(29)$ \\
\hline$>50$ & $77(16.8)$ \\
\hline \multicolumn{2}{|l|}{ HIV disease staging (\%) ${ }^{\mathrm{a}}$} \\
\hline A & 75 (16.06) \\
\hline $\mathrm{B}$ & $200(42.92)$ \\
\hline $\mathrm{C}$ & $38(8.06)$ \\
\hline \multicolumn{2}{|l|}{ HAART exposure (\%) } \\
\hline Naive & $115(24.81)$ \\
\hline 2 NRTIs + 1 NNRTI & 337 (72.79) \\
\hline 2 NRTIs + 1 PI & $10(2.2)$ \\
\hline 3 NRTIs & $1(0.2)$ \\
\hline \multicolumn{2}{|l|}{ Smoking status } \\
\hline Never & 439 (94.75) \\
\hline currently & $23(5.05)$ \\
\hline \multicolumn{2}{|l|}{ Alcohol consumption } \\
\hline Never & $293(63.3)$ \\
\hline currently & $163(35.2)$ \\
\hline \multicolumn{2}{|l|}{ Current physical exercise } \\
\hline Low & 341 (73.76) \\
\hline Moderate & $97(21)$ \\
\hline Intense & $24(5.24)$ \\
\hline
\end{tabular}

Data are means \pm standard error of means and $\mathrm{n}(\%)$; ${ }^{\mathrm{a}} \mathrm{A}$ : asymptomatic, acute HIV, or persistent generalized lymphadenopathy; B: symptomatic, not A or C categories; C: AIDS indicator conditions. HAART: Highly Active Antiretroviral Therapy; NRTI: Nucleoside Reverse Transcriptase Inhibitor, NNRTI: Non Nucleoside Reverse Transcriptase Inhibitor; PI: Protease inhibitor.

to IDF definition, this is observed in Table 2. However, the prevalence of dyslipidemia and hypertension were not showing statistically significant differences based on the 2 definitions criteria. Prevalence of metabolic syndrome in the sample was $32.8 \%(n=98)$ when using IDF criteria and $30.7 \%(n=93)$ according to ATP III (p = 0.0001).

We found that $36 \%$ of HIV-infected Cameroonian patients exposed to antiretroviral therapy had metabolic syndrome. This prevalence falls within the range of the prevalence reported in the literature (17.0\% - 45.4\%), [18]. The wide range of metabolic syndrome was attributed to the use of different definitions criteria (IDF, 32.8\%; NCEP ATP III, 30.8\%), exposition to antiretroviral therapy, different study populations and ethnic group. The prevalence obtained in the study was higher than that observed in Cameroonian general population (19.8\%) [19].

\subsection{The Prevalence of the Metabolic Syndrome and Its Individual's Components According to the Gender}

Triglycerides levels and waist circumference cut-off points are more prevalent in women than men $(p=0.0001)$. While blood pressure $(p=0.02)$ and HDL-cholesterol $(p=0.0001)$ are elevated in men. Fasting blood glucose level is the same in both sexes as shown in Table 3.

MetS occurrence was markedly higher in women. Such findings could be explained by the higher frequency of HIV-infected women compared to men. Many surveys have shown that women are more vulnerable than men. The rate for women of age between 15 - 49 (6.8\%) is higher than the rate of men in the same age group (4.1\%). Therefore, for every 100 men infected, 170 women are infected, giving an infection ratio of 1.7. This is comparable to ratios found in similar surveys in sub-Saharan Africa, particularly in Cameroon [20]. Ford [21] reported a MetS prevalence of $20.5 \%$ in Mexican-american men and 35.5\% in women. The higher predisposition of women to develop MetS could be due to biologic, psychological, and environmental factors [22]. The highest 
Table 2. Prevalence of individuals’ components of the metabolic syndrome according to IDF and ATP III definitions.

\begin{tabular}{|c|c|c|c|}
\hline Variables & IDF n (\%) & ATP III n (\%) & $\mathbf{p}$ \\
\hline Waist circumference (cm) & $118(40.5)$ & $80(26.9)$ & 0.0001 \\
\hline Blood pressure (mmHg) & $113(28.5)$ & $113(28.5)$ & NS \\
\hline HDL cholesterol (mg/dL) & $206(42.5)$ & $206(42.5)$ & NS \\
\hline Triglycerides (mg/dL) & $257(55.5)$ & $257(55.5)$ & NS \\
\hline $\mathrm{FBG}^{\mathrm{a}}(\mathrm{mg} / \mathrm{dL})$ & $92(31.2)$ & $4(1.3)$ & 0.0001 \\
\hline 3 or of the above variables (MetS) & $98(32.8)$ & $93(30.7)$ & 0.0001 \\
\hline
\end{tabular}

Data are n (\%); ${ }^{\mathrm{a}} \mathrm{FBG}$ : fasting Blood glucose; NS: not significant.

Table 3. Prevalence of individuals' components of the metabolic syndrome in relation to sex.

\begin{tabular}{|c|c|c|c|}
\hline Variables & Women n (\%) & Men n (\%) & $\mathbf{p}$ \\
\hline Waist circumference ( $\geq 90 \mathrm{~cm}$ Men $/ \geq 80 \mathrm{~cm}$ Women) & $108(56.2)$ & $10(10.1)$ & 0.0001 \\
\hline Blood pressure $\geq 130 / \geq 85 \mathrm{mmHg}$ & $50(26.5)$ & $32(32.3)$ & 0.02 \\
\hline HDL cholesterol ( $<40$ mg/dL Men/ $<50$ mg/dL Women) & $162(54.4)$ & $117(62.6)$ & 0.0001 \\
\hline Triglycerides $\geq 150 \mathrm{mg} / \mathrm{dL}$ & 166 (58.7) & $91(50.6)$ & 0.0001 \\
\hline $\mathrm{FBG}^{\mathrm{a}} \geq 100 / 110 \mathrm{mg} / \mathrm{dL}$ & $60(30.5)$ & $32(32.7)$ & NS \\
\hline 3 or of the above variables (MetS) & $88(44.4)$ & $10(9.9)$ & 0.0001 \\
\hline
\end{tabular}

prevalence of abdominal obesity, hypertriglyceridemia, low level of HDL cholesterol have also been observed in women. Increased HDL-cholesterol has been rather reported in women compared to men by some authors [23]. Some studies found an association between the number of pregnancies and obesity [24]. Moreover, menopause has an adverse effect on body composition and metabolic parameters, leading to an increased likelihood of developing obesity. Hypertriglyceridemia can be due to decreased triglycerides clearance and increased very low density lipoprotein (VLDL) overproduction [25].

\subsection{Prevalence of the Metabolic Syndrome and Its Individual Components before and after HAART Exposure}

The prevalence was greatly affected by the presence of antiretroviral therapies; it was $23.9 \%(\mathrm{n}=18)$, in naive patients and 36\% $(n=80)$ in patients on HAART $(\mathrm{p}=0.0001)$ (Table 4). The group of patients on HAART had a significantly higher plasma triglycerides $(p=0.05)$, HDL cholesterol $(p=0.04)$ levels compared to naïve patients. Elevated waist circumference cutoffs have been observed in the group under treatment $(p=0.0001)$. While fasting blood glucose level is higher in naïve than those on HAART (Table 4). The prevalence of metabolic syndrome ( $\geq 3$ components) was higher in those under therapies $(p=0.0001)$.

The prevalence of metabolic syndrome and its individual components depends on the exposition to antiretroviral therapies. Components such abdominal obesity, hypertriglyceridemia and low HDL-cholesterol had been observed in patients under therapies as compared to naive. These results agreed those obtained in many studies. Jacobson [26] reported a positive association between central accumulation of fats and HAART use. Grinspoon and Carr [27] reported the presence of low levels of HDL cholesterol in treated patients. Elevated triglyceride levels were first of all due to HIV infection but the effect was exacerbated under antiretroviral therapies [28].

\subsection{Anthropometric, Clinical Characteristics among HIV-Infected Patients with or without Metabolic Syndrome}

Patients with metabolic syndrome were more likely to have higher levels of BMI $(\mathrm{p}=0.0001)$, body fat $(\mathrm{p}=$ $0.004)$, blood pressure $(p=0.0001)$, triglycerides $(p=0.04)$, fasting glucose level $(p=0.03)$, TG/HDL ratio $(p=$ 0.006), compared to patients without metabolic syndrome (Table 5). 
Table 4. Prevalence of the metabolic syndrome and its individual components before and after HAART exposure.

\begin{tabular}{cccc}
\hline Variables & Naive n (\%) & HAART n (\%) & p \\
\hline Waist circumference (cm) & $20(26.7)$ & $98(45.4)$ & 0.0006 \\
Blood pressure (mmHg) & $15(20.3)$ & $67(31.3)$ & NS \\
HDL cholesterol (mg/dL) & $91(35.9)$ & $133(46.3)$ & 0.04 \\
Triglycerides (mg/dL) & $73(52.1)$ & $160(59.3)$ & 0.05 \\
FBG $^{\mathrm{a}}(\mathrm{mg} / \mathrm{dL})$ & $36(48.6)$ & $56(25.3)$ & 0.0001 \\
3 or of the above variables (MetS) & $18(23.4)$ & $80(36)$ & 0.0001 \\
\hline
\end{tabular}

Data are n (\%); ${ }^{\mathrm{a} F B G}$ : fasting Blood glucose; NS: not significant.

Table 5. Anthropometric, clinical characteristics among HIV-infected patients with or without MetS.

\begin{tabular}{cccc}
\hline Characteristics & $\begin{array}{c}\text { Patients without metabolic syndrome } \\
(\mathbf{n}=\mathbf{2 0 1}) \text {, mean } \pm \text { SEM }\end{array}$ & $\begin{array}{c}\text { Patients with metabolic syndrome } \\
(\mathbf{n = 9 8 )} \text { mean } \pm \text { SEM }\end{array}$ & p \\
\hline Age (years) & $36.7 \pm 0.9$ & $39 \pm 1.01$ & NS \\
Waist circumference (cm) & $79.4 \pm 0.5$ & $92.9 \pm 0.8$ & 0.0001 \\
BMI $^{\mathrm{a}}\left(\mathrm{Kg} / \mathrm{m}^{2}\right)$ & $22.6 \pm 0.2$ & $26.4 \pm 0.4$ & 0.0001 \\
Body fat & $25.8 \pm 1.5$ & $32.5 \pm 0.8$ & 0.004 \\
Blood pressure (mmHg) & $119 \pm 1.3$ & $130 \pm 2.0$ & 0.0001 \\
CD4 cell count (cells/mm $\left.{ }^{3}\right)$ & $127 \pm 21.2$ & $112 \pm 20.5$ & NS \\
Total cholesterol level (mg/dL) & $193 \pm 5.1$ & $207 \pm 8.1$ & 0.04 \\
Triglyceride level (mg/dL) & $161 \pm 6.2$ & $198 \pm 12.37$ & NS \\
HDL cholesterol level (mg/dL) & $54.6 \pm 2.1$ & $53.6 \pm 3.7$ & NS \\
LDL cholesterol level (mg/dL) & $125 \pm 0.04$ & $123 \pm 0.04$ & 0.03 \\
Fasting glucose level (mg/dL) & $93.5 \pm 3.2$ & $115 \pm 10.3$ & 0.006 \\
Atherogenicity index TG/HDL & $3.07 \pm 2.3$ & $6.25 \pm 3.3$ & NS \\
\hline Crp (mg/dL) & $20.2 \pm 3.6$ & $20.8 \pm 5.1$ & \\
\hline
\end{tabular}

Data are mean \pm SEM $=$ Mean values \pm Standard error of means, ${ }^{a}$ BMI: Body mass index.

The presence of metabolic syndrome was likely to be associated with high triglycerides, body mass index (BMI), blood pressure, fasting blood glucose levels and TG/HDL ratio as compared to those without metabolic syndrome.

The metabolic complications of patients with HIV infection introduce them to future risk of cardiovascular diseases and diabetes, despite improvement of mortality and morbidity conferred by immune reconstitution [29].

Our study has some limitations. First, the cross sectional study design of the prevalence of metabolic syndrome precludes us for examining exactly the role of each class of antiretroviral agent in the development of metabolic syndrome, longitudinal studies still to be done. Second, information on potential factors that may influence MetS such as alcohol intake, dietary habits and physical activity as well as ethnic group differences were not reported in this paper.

\section{Conclusion}

A high prevalence of metabolic syndrome was found among HIV-infected patients and mostly those under HAART. This growing prevalence is associated with gender (sex) and HAART exposure. This study indicates that HIV-infected Cameroonians showed metabolic syndrome features and are at risk of developing cardiovascular disease and type 2 diabetes; these diseases are associated with higher risk of mortality and morbidity worldwide. Furthermore, these patients who are first of all weak by the presence of HIV disease will now face the burden of non-communicable diseases, which will more affect their immune status (a dual charge). There is 
therefore a need to diagnose as early as possible these metabolic complications and initiate measures for control and prevention.

\section{Acknowledgements}

We would like to thank all people who directly or indirectly contributed to the successful completion of this study: the Ministry of Public Health of Cameroon, the day hospital staff members of the Yaounde Central Hospital, all laboratory staffs, Department of Biochemistry, Yaounde 1 University HIV infected patients and others who participated in the study.

\section{Competing Interest}

All authors: no conflicts of interest.

\section{Authors Contributions}

Conceived and designed the experiments: Julius Oben; Ngondi, J.L., Dimodi Henriette. Performed the experiments: Dimodi Henriette, Nténtie Françoise, R., Mbong Angy, M., Djiokeng Paka, G. Analyzed the data: Azantsa Kingue, B.G., Etame Sone Lucien, H. Follow up of patients: Nguimkeng, B.S., Essouman Mbappe, F., Essola Ndoe, F., Nkougni Tchinda, J., Abega Ebene, P.J. Wrote the paper: Julius Oben; Ngondi, J.L., Dimodi Henriette. All authors read and approved the final manuscript.

\section{Consent}

All authors declare that written informed consent was obtained from each participant before inclusion in the study.

\section{Ethical Approval}

The study was reviewed and approved by the National Ethics Committee (N138/CNE/SE/09) and the Ministry of Public Health (D30-47/AAR/MINSANTE/SG/DROS/CRC/CEAI, JAN 2010). The privacy of the information given remained protected all the time.

\section{References}

[1] Sterne, J.A., Hernan, M.A., Ledergerber, B., Tilling, K., Weber, R., Sendi, P., et al. (2005) Long-Term Effectiveness of Potent Antiretroviral Therapy in Preventing AIDS and Death: A Prospective Cohort Study. Lancet, 366, 378-384. http://dx.doi.org/10.1016/S0140-6736(05)67022-5

[2] Hadigan, C., Meigs, J.B., Corcoran, C., Rietschel, P., Piecuch, S., Basgoz, N., et al. (2001) Metabolic Abnormalities and Cardiovascular Disease Risk Factors in Adults with Human Immunodeficiency Virus Infection and Lipodystrophy. Clinical Infectious Diseases, 32, 130-139. http://dx.doi.org/10.1086/317541

[3] Carr, A., Samaras, K., Burton, S., Law, M., Freund, J., Chisholm, D.J. and Cooper, D.A. (1998) A Syndrome of Peripheral Lipodystrophy, Hyperlipidaemia and Insulin Resistance in Patients Receiving HIV Protease Inhibitors. AIDS, 12, 51-58. http://dx.doi.org/10.1097/00002030-199807000-00003

[4] Grundy, S.M., Brewer, H.B., Cleeman, J.I., Smith, S.C. and Lenfant, C. (2004) The American Heart Association, the National Heart, Lung and Blood Institute: Definition of Metabolic Syndrome: Report of the National Heart Association Conference on Scientific Issues Related to Definition. Circulation, 109, 433-438. http://dx.doi.org/10.1161/01.CIR.0000111245.75752.C6

[5] Lakka, H.M., Laaksonen, D., Laaka, T.A., Niskanen, L.K., Kumpusalo, E., Tuomilehto, J., et al. (2002) The Metabolic Syndrome and Total and Cardiovascular Disease Mortality in Middle-Aged Men. JAMA, 288, 2709-2716. http://dx.doi.org/10.1001/jama.288.21.2709

[6] Reaven, G.M. (2006) The Metabolic Syndrome: Is This Diagnosis Necessary? The American Journal of Clinical Nutrition, 83, 1237-1247.

[7] Saves, M., Chêne, G., Ducimetiere, P., Leport, C., Le Moal, G. and Amouyel, P. (2003) Risk Factor for Coronary Heart Diseases in Patients Treated for HIV-Infection Compared with the General Population. Clinical Infectious Diseases, 37, 292-298. http://dx.doi.org/10.1086/375844

[8] Mondy, K., Overton, E., Grubb, J., Tong, S., Seyfried, W., Powerderly, W. and Yarasheski, K. (2007) Metabolic Syn- 
drome in HIV-Infected Patients from an Urban, Midwestern US OUTPATIENT Population. Clinical Infectious Diseases, 44, 726-734. http://dx.doi.org/10.1086/511679

[9] Jerico, C., Knobel, H., Montero, M., Knobel, H., Ordonez-Llanos, J., Guelar, A, et al. (2005) Metabolic Syndrome among HIV-Infected Patients: Prevalence, Characteristics, and Related Factors. Diabetes Care, 28, 144-149. http://dx.doi.org/10.2337/diacare.28.1.132

[10] Sales, S., Campa, A., Makhema, J., Dusara, P., Tsalaile, L., Burns, P.J., et al. (2009) Metabolic Syndrome in HIV + Asymptomatic Adults in Botswana, Africa. The Journal of the Federation of American Societies for Experimental Biology, 918, 4.

[11] Mhlabi, D.B. (2011) Metabolic Syndrome among People with Human Immunodeficiency Virus on Anti-retroviral Therapy at Princess Marina Hospital in Gaborone-Botswana.

[12] Trinder, P. (1969) Determination of Blood Glucose Using an Oxydase-Peroxydase System with a Non Carcinogenic Chromogen. Journal of Clinical Pathology, 22, 158-161. http://dx.doi.org/10.1136/jcp.22.2.158

[13] Roeschlau, P., Bernt, E. and Gruber, W.A. (1974) Enzymatic Analysis of Total Cholesterol. Clinical Biochemistry, 12, 226.

[14] Buccolo, G. and David, H. (1973) Quantitative Determination of Serum Triglycerides by the Use of Enzymes. Clinical Chemistry, 19, 476-482.

[15] Friedwald, W.T., Levy, R.I. and Fredrickson, D.S. (1972) Estimation of the Concentration of Low-Density Lipoprotein Cholesterol in Plasma, without Use of Preparative Ultracentrifuge. Clinical Chemistry, 18, 499-502.

[16] NCEP-ATP III (2001) Executive Summary of the Third Report of The National Cholesterol Education Program in Adults (Adult Treatment Panel III). Journal of the American Medical Association, 285, 2486-2497. http://dx.doi.org/10.1001/jama.285.19.2486

[17] The International Diabetes Federation (2005) The IDF Consensus Worldwide Definition of Metabolic Syndrome.

[18] Worm, S.W., Friis-Moller, N., Bruyand, M., D’Arminio Monforte, A., Rickenbach, M., Reiss, P., et al. (2010) High Prevalence of the Metabolic Syndrome in HIV-Infected Patients: Impact of Different Definitions of the Metabolic Syndrome. AIDS, 24, 427-435. http://dx.doi.org/10.1097/QAD.0b013e328334344e

[19] Enyegue, D.M., Ngondi, J.L., Fomekong, G.I., Agbor, G. and Oben, J.E. (2008) Prediction and Prevalence of Metabolic Syndrome in Overweight and Obese Subject in Cameroon'. International Journal of Biomedical and Pharmaceutical Sciences, 2, 117-121.

[20] EDSC III (2004) Institut National de la Statistique, Troisième Enquête Démographique Santé, Loi nº 96, 12 du 5 Août 1996 portant Loi-c, 250 p.

[21] Ford, E.S., Gilles, W.H. and Dietz, W.H. (2002) Prevalence of the Metabolic Syndrome among US Adults: Findings from the Third National Health and Nutrition Examination Survey. JAMA, 287, 356-359. http://dx.doi.org/10.1001/jama.287.3.356

[22] Villamar, M.F., Albuja, A.C. and Salas, N.I. (2011) Metabolic Syndrome among HIV-Infected Outpatients from a Hospital in Quito, Ecuador: A Cross Sectionnal Study. Revista Panamericana Infectologia, 13, 12-18.

[23] Alencastro, P.R., Wolff, F.H., Oliveira, R.R., Ikeda, M.L., Barcellos, N.T., Brandão, A.B. and Fuchs, S.C. (2012) Metabolic Syndrome and Population Attributable Risk among HIV) AIDS Patients: Comparison between NCEPATPIII, IDF and AHA) NHLBI Definitions. AIDS Research and Therapy, 9, 29. http://dx.doi.org/10.1186/1742-6405-9-29

[24] Garcia-Garcia, E., De la Liata-Romero, M., Kaufer-Horwitz, M., Tusié-Luna, M.T., Calzada-Leon, R., VasquezVelazquez, V., et al. (2008) La Obesidad Y el Sindrome Metabolico como Problema de Salud Publica. Una Reflexion. Salud Pública de México, 50, 530-547. http://dx.doi.org/10.1590/S0036-36342008000600015

[25] Grunfeld, C., Pang, M., Doerrler, W., Shigenaga, J.K., Jensen, P. and Feingold, K.R. (1992) Lipids, Lipoproteins, Triglyceride Clearance, and Cytokines in Human Immunodeficiency Virus Infection and the Acquired Immunodeficiency Syndrome. The Journal of Clinical Endocrinology and Metabolism, 74, 1045-1052.

[26] Jacobson, D.L., Knox, T., Spiegelman, D., Skinner, S., Gorbach, S.L. and Wanke, C. (2005). Prevalence and Evolution of Fat Atrophy and Fat Deposition in a Cohort of HIV-Infected Men and Women. Clinical Infectious Diseases, 40, 1837-1845. http://dx.doi.org/10.1086/430379

[27] Grinspoon, S. and Carr, A. (2005) Cardiovascular Risk and Body Fat Abnormalities in HIV-Infected Adults. The New England Journal of Medicine, 352, 48-62. http://dx.doi.org/10.1056/NEJMra041811

[28] Riddler, S.A., Li, X., Chu, H., Kingsley, S.A., Dobs, A. and Evans, R. (2007) Longitudinal Changes in Serum Lipids among HIV-Infected Men on Highly Active Antiretroviral Therapy. HIV Medicine, 8, 280-287. http://dx.doi.org/10.1111/j.1468-1293.2007.00470.x

[29] Samaras, K. (2007) Metabolic Consequences and Therapeutic Options in Highly Active Antiretroviral Therapy in Human Immunodeficiency Virus-1 Infection. Journal of Antimicrobial Therapy Chemotherapy, 10, 1093-1100. 